\title{
À CATA DE UM BARRETE: \\ LITERATURA, CARICATURA E IMPRENSA NO BRASIL DE 1890
}

\author{
Leonardo Mendes (UERJ) \\ leop@cruiser.com.br \\ Nathalia Gorni (UERJ)
}

O romance-folhetim surgiu na França em 1830 e logo se espalhou por todo o mundo. $\mathrm{O}$ novo gênero era um produto da imprensa da era industrial. Os romances vinham publicados de forma fracionada nas reedições diárias dos jornais, tradicionalmente no rodapé da primeira página. Este espaço fora criado como um "vale-tudo" para a publicação de receitas, crônicas, contos, notícias fantasiosas, histórias de monstros etc. Era, portanto, um espaço reservado para o divertimento. Nas palavras da pesquisadora Marlyse Mayer, o folhetim "tinha uma finalidade precisa: era um espaço vazio destinado ao entretenimento" (MEYER, 1996, p. 57).

Apesar de ter surgido em 1830, o gênero só chegou ao Brasil trezes anos mais tarde, em 1843, com a publicação da obra Les mystères de Paris, por Eugène Sue (1804-1857). Nessa década, não havendo ainda uma produção representativa em português, era o folhetim francês - em tradução -, que circulava no Brasil.

Até o início do século XIX, o jornal diário tinha sido um veículo destinado quase que exclusivamente a assuntos políticos. $\mathrm{O}$ jornal tratava geralmente de temas monótonos, ligados à administração e ao comércio, voltados, portanto, para membros das elites. Com a chegada do folhetim, essa configuração mudou, pois por meio dele a imprensa buscava atingir um público mais amplo, como mulheres, donas de casa e outros leitores comuns, de modo a expandir sua distribuição e aumentar as vendas das folhas. $\mathrm{O}$ aparecimento do folhetim estava intimamente ligado à expan- 
são da leitura literária para a chamada pequena burguesia, que não podia comprar livros, mas lia jornais (TINHORÃO, 1994).

Com uma linguagem simples, acessível ao leitor comum, enredos recheados de mistérios, mas narrados com humor, povoado por fantasias e personagens divertidos, o folhetim obteve no Brasil o mesmo sucesso que obtivera na França, sendo praticado por quase todos os escritores de prosa de ficção do período. Entretanto, sua estrutura frouxa e aberta às interferências do presente inconcluso, assim como seu vínculo com o riso, foram, desde o início, considerados índices de inferioridade artística. De fato, alguns escritores procuravam até mesmo dissociar seus nomes do gênero, confirmando a impressão (ainda persistente) de que o folhetim era uma forma subalterna de literatura.

Não cabe aqui discutir os pressupostos teóricos que fundamentam tal avaliação, pois isto seria assunto para outro ensaio. Desconfiamos, entretanto, que tal julgamento escamoteia um preconceito de classe - de uma elite letrada incomodada com o fato de que as pessoas comuns tivessem vez acesso pela primeira à fruição de bens culturais, que foi a principal conquista do folhetim. $\mathrm{O}$ gênero apontava para uma proletarização do leitor e do ofício do escritor, o que foi motivo (e continua sendo) de inúmeros conflitos na instituição literária. Nesse estudo, entretanto, o folhetim, aberto e bem-humorado, será considerado uma forma legítima de literatura.

Partindo do levantamento dos romances-folhetins do jornal Gazeta de Notícias, em consulta a microfilmes depositados na Biblioteca Nacional do Rio de Janeiro, foi possível encontrar um total de quarenta e quatro romances publicados em fração naquele periódico na década de 1890. Desses, apenas três, salvo engano, foram republicados em formato de livro, como foi o caso de $O$ esqueleto, de Victor Leal, publicado originalmente no período de 17 a 31 de março de 1890; Sanatorium, de Jayme D'Athayde, publicado no período de 11 de novembro a 12 de dezembro de 1894; e Coração sem Alma, de Xavier de Monte Pinho, publicado entre o final de 1896 e o início de 1897. É curioso notar que Olavo Bilac, consagrado poeta parnasiano, estava por trás dos pseudônimos dos três folhetins da Gazeta, da década de 1890, que foram republicados em formato de livro.

Durante nossa pesquisa na Biblioteca Nacional, com Bolsa PI$\mathrm{BIC} / \mathrm{CNPq}$ junto ao projeto de pesquisa "Pequenos épicos: o romancefolhetim no Rio de Janeiro no final do século XIX", desenvolvido no 
Departamento de Letras da Faculdade de Formação de Professores da UERJ, uma ficção em particular nos chamou a atenção. Além de ser inédito, o texto se destacou por não vir propriamente publicado na seção destinada aos folhetins e por ser ilustrado. Sob o título de À Cata de um Barrete, escrito por Zé Daniel e ilustrado por Gustavo Hastoy, o romance foi publicado entre 02 a 24 de janeiro de 1890 . Ao ler a obra, notam-se semelhanças com o gênero em voga, mas também a qualidade das ilustrações diárias, os "bonecos", como Hastoy chamava suas criações, o que era incomum na época, pois eram poucos os folhetins ilustrados.

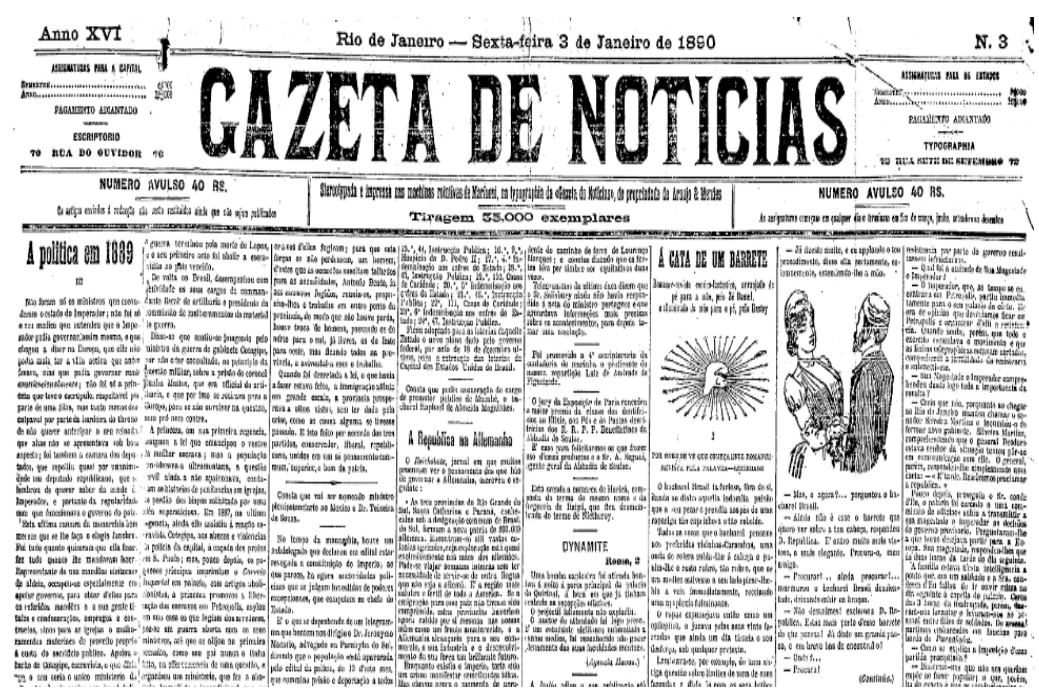

Gazeta de Notícias, 03 de janeiro de 1890

Da mesma forma que o romance-folhetim, as ilustrações, charges, caricaturas, dentre outras formas de ilustração, também ganharam espaço no jornal durante o século XIX. No Brasil, essas novidades são incorporadas a partir da década de 1850: "A imprensa apresentou no ano de 1852 algumas inovações dignas de louvor. A litografia e a gravura começaram a ilustrar os nossos jornais literários e de modas, à semelhança do que se usa na Europa" (LIMA, 1963, p. 92). No Brasil imperial, como se sabe, os jornalistas trabalhavam com bastante liberdade, o que criava um ambiente fértil para a experimentação artística:

A liberdade de imprensa viera no Primeiro Império e aumentara no Segundo, graças ao Regime parlamentar e ao espírito liberal do monarca. Pedro II concedeu atuação ampla e livre ao jornalismo todo o seu longo governo (LIMA, 1963, p. 95). 


\section{FACULDADE DE FormaÇÃo de PROFESSORES}

À Cata de um Barrete é um "romance-revista-cômico-fantástico, arranjado do pé para a mão, pelo Zé Daniel, e iluminado da mão para o pé, pelo Hastoy" - chamada da Gazeta de Notícias para a obra. Não sabemos quem foi Zé Daniel (seria um pseudônimo?) e sobre Hastoy encontramos, até agora, poucas referências (Cf. LIMA, 1963 \& STICKEL, 2004). Sabemos que ele foi um ilustrador espanhol ou húngaro, que fez muitas contribuições à imprensa fluminense no final do século XIX, especialmente à Gazeta de Notícias, onde ilustrou outros romancesfolhetins, tais como o já citado $O$ Esqueleto, de Victor Leal. Hastoy tinha aparentemente uma ligação forte com os "jovens escritores republicanos" (MENDES, 2008), com quem havia colaborado em outras aventuras jornalísticas, notadamente no semanário $O$ meio (que aparece citado em $\grave{A}$ cata de um barrete), de Paula Nei, Pardal Mallet e Coelho Neto, cujas três capas eles havia ilustrado em 1889.

Se atentarmos para a chamada do jornal, notaremos que os criadores da obra, sem preocupação com fronteiras rígidas, pensavam-na como um cruzamento de vários gêneros populares, como ensinava a tradição do folhetim. A qualificação de "revista" apontava para um diálogo com as famosas burletas de Artur Azevedo (1855-1908), que parodiavam, em cenas curtas, acontecimentos reais do cotidiano da vida política do país. Como as peças de Artur, À Cata de um Barrete era um resumo cômico do ano anterior, no qual um grupo de personagens transitava pelas ruas do Rio de Janeiro em busca de alguma coisa, o que permitia ao fio narrativo transitar por espaços sociais distintos e variados, assim como abordar os temas que haviam suscitado o interesse da população comum (Cf. VENEZIANO, 1994).

A obra conta a trajetória do bacharel Sebastião Brasil de Santa Cruz à procura de um barrete encantado que faria com que a D. República Democrática do Amor dos Povos, sua amada, se casasse com ele. Era uma forma alegórica e bem humorada de refletir sobre a construção do projeto de um país republicano, no ano seguinte ao fim da monarquia. $\mathrm{O}$ barrete, uma espécie de touca, era o símbolo do regime republicano desde a Revolução Francesa. O bacharel Brasil precisava substituir seu "chapéu-coroa" pelo barrete da D. República. A ação se passa entre 13 de maio de 1888 (abolição) e 15 de novembro de 1889 (república). 


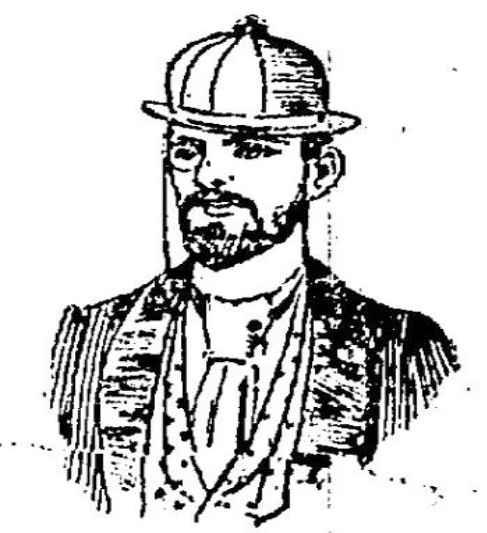

O bacharel Brasil ainda com seu "chapéu-coroa", Gustavo Hastoy, Gazeta de Notícias, janeiro de 1890

Sempre acompanhado de D. Troça, o bacharel, ingênuo e voluntarioso, vagueia pelos espaços (altos e baixos) da cidade e confronta os principais problemas do Brasil: "No dia seguinte, logo pela manhã, dirigiu-se o bacharel Brasil, com a sua inseparável companheira D. Troça, para o Largo do Rocio, onde encontrou alguns sujeitos empoleirados nas árvores do jardim" (Gazeta, 15 de janeiro de 1890). Brasil e D. Troça são de fato os protagonistas do folhetim-revista. $\mathrm{O}$ vínculo dos amigos paira acima das formas de governo. A presença constante de D. Troça garante a manutenção de um ponto de vista cômico sobre os males que afligiam o país, ao mesmo tempo em que confirmava a impressão popular de que nada era levado a sério no Brasil. Ela era "uma alegre rapariga, tafulona, de vestido de cores variadas" (Gazeta, 04 de janeiro de 1890).

Como cenas num espetáculo teatral, assistimos às investidas do bacharel em busca do barrete cobiçado e dos percalços que encontra pelo caminho. Cada capítulo diário configura um encontro com um problema ou grupo de interesses, que são sempre personificados em um ou mais personagens. Os problemas iam desde questões estruturais mais amplas (como a seca do Ceará) até deficiências que afetavam mais diretamente a população da capital, como a falta d'água e a febre amarela, que todos os verões castigava o Rio de Janeiro. Quando encontra D. Febre Amarela, de quem quer manter distância, Brasil se espanta por descobrir ser D. Troça amiga íntima daquela "senhora de véu preto e de rico vestido de seda" (Gazeta, 04 de janeiro de 1890), confirmando a dupla face do cômico. O bacharel trava contato com a Sra. Câmara Municipal Endividada 


\section{FACULDADE DE FORMAÇÃO DE PROFESSORES}

e depara-se ainda com um comício de chafarizes que, não tendo água para jorrar, decidem jorrar retórica.

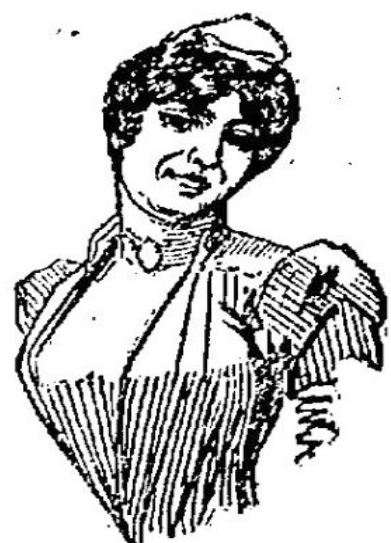

A mulher jovem e atraente como personificação da liberdade:

D. República Democrática do Amor dos Povos,

Gustavo Hastoy, Gazeta de Notícias, janeiro de 1890

Além das quedas de gabinetes ministeriais, especialmente preocupantes naquele ano de crise, vemos dois eventos-chave de 1889: o atentado ao imperador no dia 15 de julho, quando ele a imperatriz saíam de um espetáculo teatral, e o baile da ilha fiscal no dia 09 de novembro em homenagem a militares chilenos em passagem pelo Rio. Foram três tiros disparados contra o carro de Pedro II naquela noite, mas nenhum atingiu o alvo. Na ocasião o bacharel dividia uma garrafa de cerveja com D. Troça na Maison Moderne, uma das confeitarias mais frequentadas da cidade:

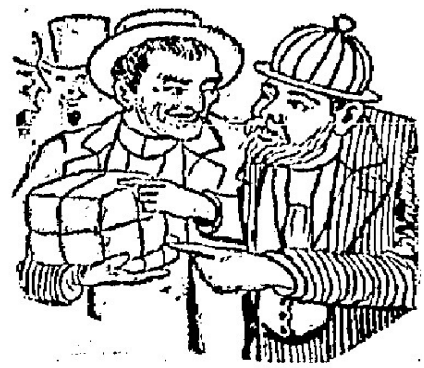

O bacharel Brasil é enganado por um "senhor respeitável" com um embrulho de dinheiro falso,

Gustavo Hastoy, Gazeta de Notícias, janeiro de 1890 
Acabava D. Troça de proferir estas palavras, quando ouviu-se um tiro, seguido de grande rumor.

A Maison Moderne foi, ato contínuo, invadida por muitas pessoas.

- Que aconteceu? Perguntou o bacharel a um dos que a correr vinham do Largo do Rocio.

- Deram um tiro no carro imperial! Vou prevenir a polícia.

E o sujeito, tendo dito isto, foi despertar Mme. Polícia, que nesse momento roncava a bom roncar.

- Ó senhora! Bradava o tal indivíduo, sacudindo Mme. Polícia; acorde! Acorde!

- É algum gatuno? Perguntou esta, acordando a muito custo, e bocejando. Cá tenho o meu apito... Disfarcemos.

- E já se dispunha a apitar, quando lhe disse o mesmo indivíduo:

- Qual gatuno! Acabam de dar um tiro em direção ao carro imperial!

- Ah! Disse muito pachorrentamente Mme. Polícia. Isso agora é outro caso! Pois sim! Pois sim! Amanhã havemos de ver isso.

- E abaixando a cabeça, Mme. Polícia ferrou de novo no sono (Gazeta, 14 de janeiro de 1890).

Mademoiselle Polícia era preguiçosa e inepta. O bacharel descobre que ela tinha apito "para disfarçar e olhos para não ver", confirmando a impressão popular persistente de que os órgãos de manutenção da ordem pública não eram confiáveis. Mademoiselle não conseguia encontrar as três balas perdidas, mas fazia alarde nas buscas. Alarmado, o regime imperial apertou a repressão às dissidências, que Hastoy imaginou como uma teia de aranha que apertasse os braços de D. República.

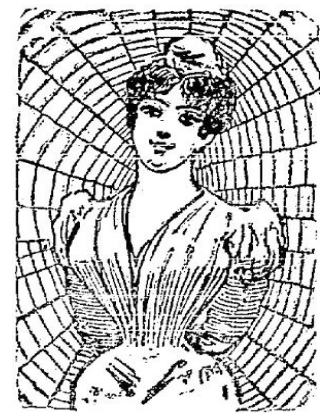

D. República presa na teia de aranha, Gustavo Hastoy, Gazeta de Notícias, janeiro de 1890 


\section{FACULDADE DE FORMAÇÃO DE PROFESSORES}

- Tu por aqui! Exclamou o bacharel. Pois não te assusta a polícia?! Mas que laços são esses que te prendem os baços?

- Teias de aranha, respondeu a rir D. República. A pobre velha D. Polícia, supondo manietar-me, fez isto que vês. Ligou-me, apertou-me os braços com estas teias de aranha, que lá na sua infantil imaginação tem o valor de rijas correntes de ferro! Tola e presumida! Como se porventura pudesse ela tolherme os movimentos! (Gazeta, 15 de janeiro de 1890).

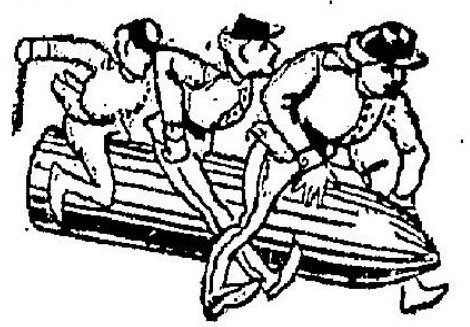

A polícia montada na bala em perseguição à $\mathrm{D}$. República,

Gustavo Hastoy, Gazeta de Notícias, janeiro de 1890

Brasil foi ao baile da ilha fiscal na esperança de que algum oficial chileno the dissesse onde podia encontrar o barrete, mas lá encontra a "encantadora" D. República, que lhe avisa estar próximo o dia de sua aliança com o bacharel. A senhora estava finalmente convencida da "constância e da firmeza" do amor que o Brasil lhe devotava. De fato, alguns dias depois, como num sonho, o bacharel se vê no Campo de Santana (atual Praça da República) festejando seu casamento com D. República. Um guerreiro de "fisionomia majestosa e serena /.../ arrancou-lhe o chapéu-coroa e, entre delirantes vivas e aclamações, substituiu-o por um barrete" (Gazeta, 24 de janeiro de 1890).

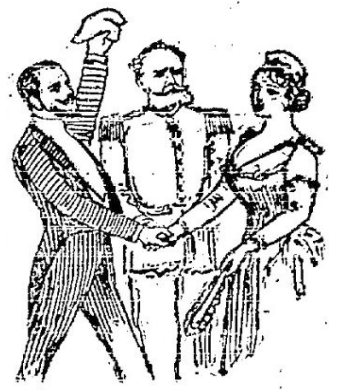

O enlace entre o bacharel Brasil e a D. República, com o barrete na mão esquerda, Gustavo Hastoy, Gazeta de Notícias, janeiro 1890 
O papel decisivo dos militares na troca de regimes é explicitado pelo romance-revista. O marechal Deodoro da Fonseca (1827-1892) aparece como um guerreiro altivo e elegante, atestando o prestígio de que gozavam as Forças Armadas no ocaso do império.

Sem nenhum compromisso com a verossimilhança, a ficção de Zé Daniel e Gustavo Hastoy passava em revista, como numa peça de teatro popular, os principais acontecimentos do turbulento ano de 1889 , sempre de forma paródica e bem-humorada. A linguagem coloquial aproximava o leitor comum do folhetim, assim como as incríveis ilustrações de Hastoy tornavam ainda mais acessível e atraente a ficção e o jornal Gazeta de Notícias - o primeiro órgão da grande imprensa carioca a atingir a cifra de dezenas de milhares de exemplares vendidos diariamente (MINÉ, 2005). À cata de um barrete era uma forma popular de ficção que aceitava e celebrava o colapso das distinções e hierarquias tradicionais entre os gêneros, apostando na importância da imagem para a fruição narrativa, dentro da mais "alta" tradição do "vale-tudo" do folhetim.

\section{REFERÊNCIAS BIBLIOGRÁFICAS}

DU TERRAIL, Ponson. As aventuras de Rocambole. Rio de Janeiro: Nova Fronteira, 1977.

FERREIRA, Jorge; DELGADO, Lucélia de A. Neves. O Brasil Republicano: o tempo do liberalismo excludente, v. 1. Rio de Janeiro: Civilização Brasileira, 2003.

LIMA, Herman. História da caricatura no Brasil. Rio de Janeiro: José Olympio, 1963.

MENDES, Leonardo. O copeiro de Aluísio Azevedo: transgressão, boemia e marginalidade no romance brasileiro do final do século XIX. In: LAGE, Verônica Lucy Coutinho (Org.). Literatura, crítica e cultura II: diálogos com Machado de Assis, caminhos da crítica literária. Juiz de Fora: UFJF, 2008a, p. 95-113.

- O romance republicano: naturalismo e alteridade no Brasil (1880-1890). Letras \& Letras, Uberlândia, Universidade Federal de Uberlândia, v. 24, n. 2, jul.dez.2008b, p. 189-207.

MÉRIAN, Jean-Yves. Aluísio Azevedo: vida e obra. Rio de Janeiro: Espaço e Tempo Banco Sudameris, 1988. 


\section{FACULDADE DE FORMAÇÃO DE PROFESSORES}

MEYER, Marlyse. Folhetim: uma história. São Paulo: Cia. das Letras, 1996.

. As mil faces de um herói-canalha e outros ensaios. Rio de Janeiro: UFRJ, 1998.

MINÉ, Elza. Ferreira de Araújo, ponte entre o Brasil e Portugal. Via Atlântica, n. 8, dez 2005, p. 221-229.

STICKEL, Erico Siriúba. Uma pequena biblioteca particular: subsídios para o estudo da iconografia no Brasil. São Paulo: EDUSP, 2004.

TINHORÃO, José Ramos. Os romances em folhetim no Brasil: 1830 à atualidade. São Paulo: Duas Cidades, 1994.

VENEZIANO, Neyde. O teatro de revista. In: FRAGALE, Carlinda. $O$ teatro através da história. Rio de Janeiro: Centro Cultural Banco do Brasil, 1994, v. 2. 